\title{
Evaluation of Role of Centrally Acting Skeletal Muscle Relaxants During Tooth Preparation Procedure. An INVIVO Study
}

\author{
Harsh Kasabwala ${ }^{1}$ and Dhanraj .M. Ganapathy ${ }^{2}$ \\ ${ }^{1}$ Department of Prosthodontics Saveetha Dental College and Hospitals Saveetha \\ Institute of Medical And Technical Sciences Saveetha University, Chennai, India \\ ${ }^{2}$ Department of prosthodontics Saveetha Dental College and Hospitals Saveetha \\ Institute Of Medical And Technical Sciences Saveetha University, Chennai, India
}

\section{ABSTRACT}

Skeletal muscle relaxants have been widely used in the medical field for carrying out various treatment procedures. There have been very few studies that have shown the use of muscle relaxants in carrying out dental procedures. This study aims at evaluating the advantage of administering centrally acting muscle relaxants (chlorzoxazone) before starting tooth preparation procedure. 40 patients who required tooth preparation procedure for example in cases of fixed partial denture, full mouth rehabilitation cases , cast partial denture cases satisfying the following inclusion and exclusion criteria were randomly allocated to two groups, A and B using coin flip method. Group A patients were administered with chlorzoxazone. Group B patients were administered with a placebo drug. The results reveal that there is a significant difference in the pain and discomfort experienced by the patients after the administration of skeletal muscle relaxants during tooth preparation procedure. The mouth opening of the patients was significantly better in patients administered with the muscle relaxant (chlorzoxazone). Centrally acting skeletal muscle relaxants can be administered during tooth preparation procedures, in order to increase patient comfort and operator efficiency.

KEY WORDS: SKELETAL MUSCLE RELAXANTS, CHLORZOXAZONE, BACLOFEN, PATIENT COMFORT, PAIN, MOUTH OPENING , MUSCLE SPASM.

\section{INTRODUCTION}

Tooth preparation is a procedure in which the tooth morphology is altered in order to receive a prosthesis. This procedure requires a lot of precision and involves a lot of steps and principles(Tiu et al., 2016). A lot of factors

\section{ARTICLE INFORMATION}

*Corresponding Author: dhanraj@saveetha.com

Received 15th June 2020 Accepted after revision 10th August 2020 Print ISSN: 0974-6455 Online ISSN: 2321-4007 CODEN: BBRCBA

Thomson Reuters ISI Web of Science Clarivate Analytics USA and Crossref Indexed Journal

\section{Clarivate}

NAAS Journal Score 2020 (4.31) SJIF: 2020 (7.728)

A Society of Science and Nature Publication,

Bhopal India 2020. All rights reserved.

Online Contents Available at: http//www.bbrc.in/

Doi: http://dx.doi.org/10.21786/bbrc/13.7/27 have to be taken into consideration in order to carry out an ideal crown preparation. It is necessary to preserve remaining tooth structure. Provision on resistance and retention form plays and integral part in crown preparation. The preparation should have good structural durability . One of the most important factors is provision of ideal margins.(Kishimoto, Shillingburg and Duncanson, 1983) All these factors make this procedure quite time consuming, especially in full mouth rehabilitation cases where multiple teeth have to be prepared .These cases are quite tiring and stressful both for the patient as well as the operator. 
The patient has to keep his mouth opened for a long period of time. This by itself causes a lot of stress on the masticatory muscles and temporomandibular joint (Laskin and Block, 1986). Patient experiences muscular spasms and pain in the temporomandibular joint region due to continuous tension on the muscles. Dentist must be aware on the proper diagnosis and treatment of facial muscle pain (Cooper and Rabuzzi, 1984), because they represent one of the most frequent patient complaint during long dental procedures especially during tooth preparation appointments and root canal treatment cases(Laskin and Block, 1986). Skeletal muscle relaxants are frequently used to treat these conditions. The muscle relaxants are believed to exert their action either by treating spasticity secondary to upper motor neuron syndromes, or muscular pain and spasms(Fukushima and Ochiai, 2013). Jaw soreness and stiffness can be present due to muscle strain after any kind of dental procedure that requires you to keep your mouth open for an extended period of time.

A slightly sore jaw is considered to be normal after long dental treatments. There is a high possibility that the patient might complain of inability to keep the mouth open and also the patient might experience facial muscles becoming stiff causing a locked jaw(Love, 1970) (Domino, 1964). In order to avoid these consequences a better and a more efficient option would possibly be to prophylactically administer the patient with skeletal muscle relaxants preoperatively. This might help in carrying out the dental treatment smoothly and much more efficiently. Previously our department has published extensive research on various aspects of prosthetic dentistry ('Evaluation of Corrosive Behavior of Four Nickel-chromium Alloys in Artificial Saliva by Cyclic Polarization Test:An in vitro Study', 2017; Ganapathy, Kannan and Venugopalan, 2017; Jain, 2017a, 2017b; Ranganathan, Ganapathy and Jain, 2017; Ariga et al., 2018b; Gupta, Ariga and Deogade, 2018; Anbu et al., 2019; Ashok and Ganapathy, 2019; Duraisamy et al., 2019; Varghese, Ramesh and Veeraiyan, 2019).

('Evaluation of Corrosive Behavior of Four Nickelchromium Alloys in Artificial Saliva by Cyclic Polarization Test:An in vitro Study', 2017; Ganapathy, Kannan and Venugopalan, 2017; Jain, 2017a, 2017b; Ranganathan, Ganapathy and Jain, 2017; Ariga et al., 2018b; Gupta, Ariga and Deogade, 2018; Anbu et al., 2019; Ashok and Ganapathy, 2019; Duraisamy et al., 2019; Varghese, Ramesh and Veeraiyan, 2019)('Evaluation of Corrosive Behavior of Four Nickel-chromium Alloys in Artificial Saliva by Cyclic Polarization Test:An in vitro Study', 2017; Ganapathy, Kannan and Venugopalan, 2017; Jain, 2017a, 2017b; Ranganathan, Ganapathy and Jain, 2017; Ariga et al., 2018b; Gupta, Ariga and Deogade, 2018; Anbu et al., 2019; Ashok and Ganapathy, 2019; Duraisamy et al., 2019; Varghese, Ramesh and Veeraiyan, 2019), this vast research experience has inspired us to research about this topic. Considering the above factors discussed, this present study aims at evaluating the role and effectiveness of skeletal muscle relaxants when they are administered preoperatively during tooth preparation procedures.

\section{MATERIAL AND METHODS}

The present study was presented before the institutional ethical and scientific review board and permission was obtained. The study protocol conformed to the ethical guidelines prescribed by the WHO and Helsinki declaration.

Study type: The present study is an invivo interventional trial involving human subjects.

Study design: Randomised control trial with parallelling group design.

\section{Estimation of sample size:}

Selection of subjects: 20 patients who required tooth preparation procedure for example in cases of fixed partial denture, full mouth rehabilitation cases, cast partial denture cases satisfying the following inclusion and exclusion criteria were randomly allocated to two groups, A and B respectively.

Inclusion criteria: Patients with preferably multiple missing teeth, age within 20 to 70 years, both male and female, without any temporomandibular joint problems or any kind of facial muscle disorders and limited mouth opening, with willingness to participate in the study.

Exclusion criteria: Patients with poor oral hygiene, patient undergoing implant supported prosthetic treatment, patients with temporomandibular joint problems, patients with limited mouth opening. Informed consent: The selected subjects were clearly explained about the study protocols and informed consent was obtained from them for participation.

Random allocation: The selected subjects were randomly allocated into 2 groups A and B respectively using the coin flip method. Patients in Group A will receive preoperative administration with chlorzoxazone. Patients in group B will receive preoperative administration with a placebo drug with looks exactly like the test drug.

Outcome measures: Amount of mouth opening after the procedure using interincisal distance as reference. Evaluation of postoperative muscle pain after the procedure using VAS scale. Evaluation of post operative muscle spasm after the procedure. Evaluation of amount of patient comfort post operatively. Single blinding of the operator was observed.

\section{RESULTS AND DISCUSSION}

The mean and standard deviation values for patients of Group A and B are $5.50 \pm 1.14$ and $3.50 \pm 0.889$ respectively in case of postoperative pain. The mean and standard deviation values for patients of Group A and Group B are $5.25 \pm 1.11$ and $3.40 \pm 1.09$ in case 
of discomfort experienced. The mean and standard deviation values for patients of Group A and Group $\mathrm{B}$ are $38 \pm 2.65$ and $39 \pm 1.53$ respectively in case of postoperative mouth opening.

The association between the administration of skeletal muscle relaxant and post operative pain experienced by the patient was statistically significant [unpaired $t$ test association value-0.001] [p-value $>0.05$ ]. The association between the administration of skeletal muscle relaxant and post operative discomfort experienced by the patient was statistically significant [unpaired t test association value - 0.001] [p-value $>0.05$ ]. The association between the administration of skeletal muscle relaxant and improvement in postoperative mouth opening of the patient was statistically significant [unpaired test association value - 0.009] [p-value $>0.05$ ]

There are not many studies regarding the postoperative effects that patients experience after of tooth preparation procedures especially in full mouth rehabilitation cases where multiple teeth have to be prepared.The purpose of this study was to obtain evidence regarding the efficacy of chlorzoxazone during tooth preparation . This study intended the use of chlorzoxazone to reduce patient's discomfort and increase Intra operative functional capacity.

Muscle spasticity is seen in many clinical conditions, including trauma,, muscular and ligamentous sprains and strains, intervertebral disc disease, tetanus, neurologic disorders, and exertional rhabdomyolysis. Increased in tonic stretch reflexes originates from the CNS with involvement of descending pathways and results in hyperexcitability of motor neurons in the spinal cord. Drug therapy alleviates muscle spasms by modifying the stretch reflex arc or by interfering with the excitationcoupling process in the muscle itself. Muscle relaxants which act centrally block interneuronal pathways in the midbrain reticular activating system and spinal cord. Some drugs also have sedative effects(Fingeroth et al., 2014)

The presence of acute facial muscle pain and muscle spasm is a common finding during long dental procedures. Many centrally acting skeletal muscle relaxants are being used to relieve these conditions. Familiar members of this class of drugs include carisoprodol (Soma), chlorzoxazone (Paraflex), cyclobenzaprine (Flexeril), metaxalone (Skelaxin), methocarbamol (Robaxin), baclofen (Lioresal), and tizanidine (Zanaflex). Most commonly used among all these drugs is chlorzoxazone. (Love, 1970) . Chlorzoxazone has limited number of reported cases of significant hepatotoxicity in individuals taking this drug as compared to other muscle relaxants. Chlorzoxazone has a plasma half-life of 1 to 2 hours. Its onset of acation is within 1 hour. The duration of action is 3 to 4 hours (Williams and Leuwer, 2010).

Cyclobenzaprine, carisoprodol, and chlorzoxazone are a few drugs that have proved to be more effective than placebo in treating patients suffering from muscle spasms These drugs in combination with NSAIDs, help in augmenting the efficacy of the NSAID. NSAID and a muscle relaxant combination offers significant relief of pain when compared with other therapies, including those with narcotics. The major side effects of muscle relaxants are drowsiness, headache, dizziness, and dry mouth(Isaac and Katz, 2011). The drug of interest in this study (chlorzoxazone) being more freely available and having comparatively lesser side effects was thus chosen for the study.

Chlorzoxazone has several uses in the field of medicine. It is a synthetic compound that inhibits antigen-induced bronchospasms and, hence, is used to treat asthma and allergic rhinitis. Chlorzoxazone is mainly used in combination with acetaminophen , they do have some drawbacks and side effects(Liederman, 1967). Chlorzoxazone is used as an adjunct drug to treat conjunctivitis and to treat systemic mastocytosis and ulcerative colitis and musculoskeletal conditions. Spinal cord and subcortical areas of the brain are affected by the drug very efficiently as chlorzoxazone mainly inhibits multisynaptic reflex arc that is involved in maintaining skeletal muscle spasm of different etiology. The clinical result is a reduction of the skeletal muscle spasm with relief of pain and increased mobility of the involved muscles.(Dong et al., 2006).

Diazepam another centrally acting muscle relaxant is very efficient in relieving muscular spasms, seizures and depression(Chapa, 2018). The activity of a new muscle-relaxant, DS 103-282, was compared with that of diazepam in a randomized double-blind study on patients suffering from acute muscular spasm . It was found to reduce symptoms and improve mobility to a significant degree in all parameters evaluated and was also significantly superior to diazepam. DS 103-282 had a rapid onset of action. Both medications were well tolerated and there was no significant difference between them.(Hennies, 1981) Diazepam by itself has several side effects like severe nausea, confusion, the patient may also develop addiction. Long term use is not advisable for diazepam or rather any skeletal muscle relaxants for that matter (Craig and Fielding, 1982),(Wada, 1996)

Its mechanism of action involves inhibition of degranulation of mast cells, subsequently preventing the release of histamine and slow-reacting substance of anaphylaxis (SRS-A), mediators of type I allergic reactions. The release of inflammatory leukotrienes may also be reduced by chlorzoxazone. Chlorzoxazone may act by repressing calcium and potassium convergence which would prompt neuronal hindrance and muscle spasms (Rinaldi et al., 1987) Data available from animal experiments as well as human study indicate that chlorzoxazone acts fundamentally at the dimension of the spinal cord and subcortical zones of the brain where it hinders multisynaptic reflex segments associated with creating and keeping up skeletal muscle tone(Wan et al., 2006). 
This medication may rarely cause very serious (possibly fatal) liver disease and may also develop symptoms of liver disease, including: persistent nausea/vomiting, stomach/abdominal pain, yellowing eyes/skin, dark urine. But they are mainly observed in long term usage. It does not have a lot of major side effects when it is used for a couple of times for example before any long duration dental procedure.there are many studies wherein centrally acting skeletal muscle relaxants are administered after dental procedures. Many studies have been done which suggest administration of corticosteroids and skeletal muscle relaxants postoperatively in order to relive the spasm and discomfort. (Rood, Yates and Buchanan, 1979; Ata-Ali et al., 2011). There are no studies that suggest administration of centrally acting skeletal muscle relaxants preoperatively in cases of tooth preparation. Based on the results obtained from the statistical data there was a significant difference in relation to pain, discomfort, and mouth opening of the patient when a centrally acting muscle relaxant was administered.

\section{CHARTS AND FIGURES}

Table 1. This table shows the association between the administration of skeletal muscle relaxant and post operative pain, discomfort and mouth opening. The association between the administration of skeletal muscle relaxant and post operative pain experienced by the patient was statistically significant [unpaired t test association value - 0.001] [p-value $>0.05$ ] The association between the administration of skeletal muscle relaxant and post operative discomfort experienced by the patient was statistically significant [unpaired t test association value - 0.001] [p-value>0.05]. The association between the administration of skeletal muscle relaxant and improvement in postoperative mouth opening of the patient was statistically significant [unpaired t test association value - 0.009] [p-value>0.05].

\begin{tabular}{|l|c|c|c|}
\hline VARIABLES & $\begin{array}{c}\text { Group A- Patients without } \\
\text { administration of the drug } \\
\mathrm{n}=\mathbf{2 0}\end{array}$ & $\begin{array}{c}\text { Group B - Patients with } \\
\text { drug administration } \\
\mathrm{n}=20 \text { (Chlorzoxazone) }\end{array}$ & P value \\
\hline $\begin{array}{l}\text { Postoperative pain } \\
\text { Postoperative discomfort }\end{array}$ & $5.25 \pm 1.11$ & $3.50 \pm 0.889$ & 0.001 \\
\hline $\begin{array}{l}\text { Post operative mouth } \\
\text { opening }\end{array}$ & $38 \pm 2.65$ & $3.40 \pm 1.09$ & 0.001 \\
\hline
\end{tabular}

Figure 1: This figure shows the difference between the means of post operative pain experienced by the population lying in the 2 groups. Group A represents the population not administered with chlorzoxazone and Group B represents the group administered with chlorzoxazone. It can be seen in the figure that the postoperative pain experienced by patients of Group A was higher as compared to that of Group B suggesting that administration of chlorzoxazone was effective in reducing post operative pain after tooth preparation procedure

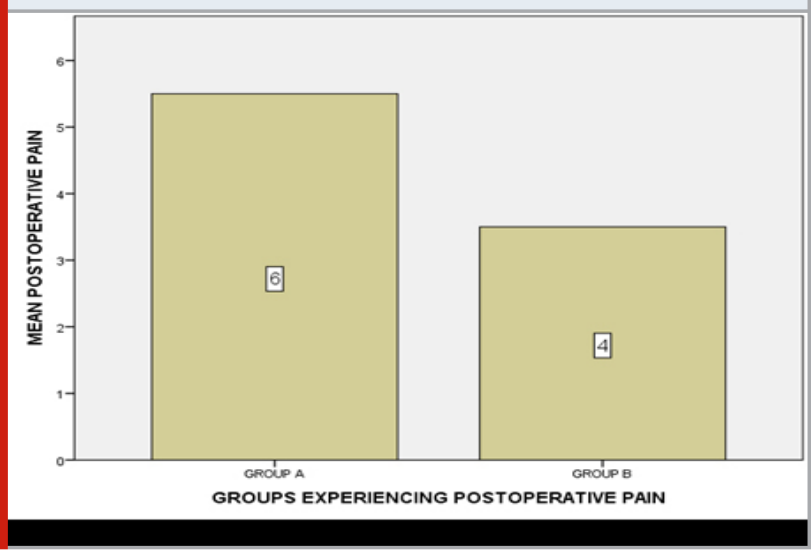

\section{CONCLUSION}

There have not been many studies describing pre operative administration with skeletal muscle relaxants during tooth preparation procedure.Based on the results obtained from the study it can be concluded that centrally acting skeletal muscle relaxants when used wisely keeping in mind the side effects can be used to significantly to reduce the patient discomfort, improve post operative mouth opening and reduce pain. This helps in improving overall operator efficiency.

\section{ACKNOWLEDGEMENTS}

This research was done under the research department of Saveetha dental College and hospitals. We sincerely provide gratitude and are very thankful to the guide who helped in making this study possible.

Author Contributions: Author 1- Harsh Kasabwala carried out the study by collecting the raw data handwriting the manuscript with the necessary statistical analysis. Author 2 -Dr Dhanraj Ganapathy helped in guiding the study and supervised the statistics.

Conflict of Interest: There was no conflict of interest among the authors 


\section{REFERENCES}

Ajay, R. et al. (2017) 'Effect of surface modifications on the retention of cement-retained implant crowns under fatigue loads: An In vitro study', Journal of Pharmacy And Bioallied Sciences, p. 154. doi: 10.4103/ jpbs.jpbs_146_17.

Anbu, R. T. et al. (2019) 'Comparison of the Efficacy of Three Different Bone Regeneration Materials: An Animal Study', European journal of dentistry, 13(1), pp. 22-28.

Ariga, P. et al. (2018a) 'Determination of Correlation of Width of Maxillary Anterior Teeth using Extraoral and Intraoral Factors in Indian Population: A Systematic Review', World Journal of Dentistry, pp. 68-75. doi: 10.5005/jp-journals-10015-1509.

Ariga, P. et al. (2018b) 'Determination of Correlation of Width of Maxillary Anterior Teeth using Extraoral and Intraoral Factors in Indian Population: A Systematic Review', World Journal of Dentistry, 9(1), pp. 68-75. Ashok, V. et al. (2014) 'Lip Bumper Prosthesis for an Acromegaly Patient: A Clinical Report', The Journal of Indian Prosthodontic Society, pp. 279-282. doi: 10.1007/ s13191-013-0339-6.

Ashok, V. and Ganapathy, D. (2019) 'A geometrical method to classify face forms', Journal of oral biology and craniofacial research, 9(3), pp. 232-235.

Ashok, V. and Suvitha, S. (2016) 'Awareness of all ceramic restoration in rural population', Research Journal of Pharmacy and Technology. A \& V Publications, 9(10), pp. 1691-1693.

Ata-Ali, J. et al. (2011) 'Corticosteroids use in controlling pain, swelling and trismus after lower third molar surgery use in controlling pain, swelling and trismus after lower third molar surgery', Journal of Clinical and Experimental Dentistry, pp. e469-e475. doi: 10.4317/ jced.3.e469.

Basha, F. Y. S., Ganapathy, D. and Venugopalan, S. (2018) 'Oral Hygiene Status among Pregnant Women', Research Journal of Pharmacy and Technology, p. 3099. doi: 10.5958/0974-360x.2018.00569.3.

Chapa, Y. (2018) Diazepam: Perfect Treatment for Trouble Sleeping, Muscle Spasm, Seizure and Depression. Createspace Independent Publishing Platform.

Cooper, B. C. and Rabuzzi, D. D. (1984) 'Myofacial pain dysfunction syndrome: A clinical study of asymptomatic subjects', The Laryngoscope, pp. 68-75. doi: 10.1002/ lary.5540940116.

Craig, M. and Fielding, J. F. (1982) 'Drug efficacy and side effects following different formulations of intravenous diazepam', Irish Journal of Medical Science, pp. 79-80. doi: 10.1007/bf02940151.

Domino, E. F. (1964) ‘Centrally Acting Skeletal Muscle
Relaxants', Evaluation of Drug Activities, pp. 313-324. doi: 10.1016/b978-1-4832-2845-7.50021-9.

Dong, D.-L. et al. (2006) 'Chlorzoxazone inhibits contraction of rat thoracic aorta', European journal of pharmacology, 545(2-3), pp. 161-166.

Duraisamy, R. et al. (2019) 'Compatibility of Nonoriginal Abutments With Implants: Evaluation of Microgap at the Implant-Abutment Interface, With Original and Nonoriginal Abutments', Implant dentistry, 28(3), pp. 289-295.

Evaluation of Corrosive Behavior of Four Nickelchromium Alloys in Artificial Saliva by Cyclic Polarization Test:An in vitro Study' (2017) World Journal of Dentistry, 8(6), pp. 477-482.

Fingeroth, J. M. et al. (2014) 'Nonsteroidal Antiinflammatory Drugs, Muscle Relaxants, Opioids, and Other Treatments for Primary and Adjunctive Medical Management of Intervertebral Disc Herniation', Advances in Intervertebral Disc Disease in Dogs and Cats, pp. 186-193. doi: 10.1002/9781118940372.ch24. Fukushima, K. and Ochiai, R. (2013) Muscle Relaxants: Physiologic and Pharmacologic Aspects. Springer Science \&t Business Media.

Ganapathy, D. et al. (2016) 'Effect of Resin Bonded Luting Agents Influencing Marginal Discrepancy in All Ceramic Complete Veneer Crowns', Journal of clinical and diagnostic research: JCDR, 10(12), pp. ZC67-ZC70.

Ganapathy, D. M., Kannan, A. and Venugopalan, S. (2017) 'Effect of Coated Surfaces influencing Screw Loosening in Implants: A Systematic Review and Meta-analysis', World Journal of Dentistry, 8(6), pp. 496-502.

Gupta, P., Ariga, P. and Deogade, S. C. (2018) 'Effect of Monopoly-coating Agent on the Surface Roughness of a Tissue Conditioner Subjected to Cleansing and Disinfection: A Contact Profilometric Study', Contemporary clinical dentistry, 9(Suppl 1), pp. S122S126.

Hennies, 0. L. (1981) 'A new skeletal muscle relaxant (DS 103-282) compared to diazepam in the treatment of muscle spasm of local origin', The Journal of international medical research, 9(1), pp. 62-68.

Isaac, Z. and Katz, J. N. (2011) 'Lumbar spine disorders', Rheumatology, pp. 659-681.e3. doi: 10.1016/b978-0323-06551-1.00069-5.

Jain, A. R. (2017a) 'Clinical and Functional Outcomes of Implant Prostheses in Fibula Free Flaps', World Journal of Dentistry, 8(3), pp. 171-176.

Jain, A. R. (2017b) 'Prevalence of Partial Edentulousness and Treatment needs in Rural Population of South India', World Journal of Dentistry, 8(3), pp. 213-217. Jain, A., Ranganathan, H. and Ganapathy, D. (2017) 
'Cervical and incisal marginal discrepancy in ceramic laminate veneering materials: A SEM analysis', Contemporary Clinical Dentistry, p. 272. doi: 10.4103/ ccd.ccd_156_17.

Jyothi, S. et al. (2017) 'Periodontal Health Status of Three Different Groups Wearing Temporary Partial Denture', Research Journal of Pharmacy and Technology, p. 4339. doi: 10.5958/0974-360x.2017.00795.8.

Kannan, A. and Venugopalan, S. (2018) 'A systematic review on the effect of use of impregnated retraction cords on gingiva', Research Journal of Pharmacy and Technology, p. 2121. doi: 10.5958/0974360x.2018.00393.1.

Kishimoto, M., Shillingburg, H. T. and Duncanson, M. G. (1983) 'Influence of preparation features on retention and resistance. Part II: Three-quarter crowns', The Journal of Prosthetic Dentistry, pp. 188-192. doi: 10.1016/0022-3913(83)90498-5.

Laskin, D. M. and Block, S. (1986) 'Diagnosis and treatment of myofacial pain-dysfunction (MPD) syndrome', The Journal of prosthetic dentistry, 56(1), pp. 75-84.

Liederman, P. C. (1967) 'Psychic Side Effects of a Chlorzoxazone and Acetaminophen Mixture', JAMA, p. 64. doi: 10.1001/jama.1967.03130140122029.

Love, T. E. (1970) A Study of the Effect of Chlorzoxazone and Acetaminophen, a Combination Drug, on Postoperative Trismus: Thesis Submitted in Partial Fulfillment ... Oral Surgery.

Ranganathan, H., Ganapathy, D. M. and Jain, A. R. (2017) 'Cervical and Incisal Marginal Discrepancy in Ceramic Laminate Veneering Materials: A SEM Analysis', Contemporary clinical dentistry, 8(2), pp. 272-278.

Rinaldi, G. J. et al. (1987) 'Dissociation between calcium influx blockage and smooth muscle relaxation by nifedipine in spontaneously hypertensive rats', Circulation Research, pp. 367-374. doi: 10.1161/01. res.60.3.367.

Rood, J. P., Yates, C. and Buchanan, M. (1979)
'Postoperative swelling and trismus after mandibular third molar removal with the lingual split bone technique', International Journal of Oral Surgery, pp. 31-35. doi: 10.1016/s0300-9785(79)80036-8.

Selvan, S. R. and Ganapathy, D. (2016) 'Efficacy of fifth generation cephalosporins against methicillin-resistant Staphylococcus aureus-A review', Research Journal of Pharmacy and Technology, p. 1815. doi: 10.5958/0974360x.2016.00369.3.

Subasree, S., Murthykumar, K. and Dhanraj (2016) 'Effect of Aloe Vera in Oral Health-A Review', Research Journal of Pharmacy and Technology, p. 609. doi: 10.5958/0974-360x.2016.00116.5.

Tiu, J. et al. (2016) 'Convergence angles and margin widths of tooth preparations by New Zealand dental students', The Journal of prosthetic dentistry, 116(1), pp. 74-79.

Varghese, S. S., Ramesh, A. and Veeraiyan, D. N. (2019) 'Blended Module-Based Teaching in Biostatistics and Research Methodology: A Retrospective Study with Postgraduate Dental Students', Journal of dental education, 83(4), pp. 445-450.

Venugopalan, S. et al. (2014) 'Magnetically retained silicone facial prosthesis', Nigerian journal of clinical practice, 17(2), pp. 260-264.

Vijayalakshmi, B. and Ganapathy, D. (2016) 'Medical management of cellulitis', Research Journal of Pharmacy and Technology, p. 2067. doi: 10.5958/0974360x.2016.00422.4.

Wada, H. (1996) 'Side effects of diazepam administered to prevent febrile seizure recurrence', Brain and Development, p. 478. doi: 10.1016/s03877604(97)83012-4.

Wan, J. et al. (2006) 'Chlorzoxazone metabolism is increased in fasted Sprague-Dawley rats', The Journal of pharmacy and pharmacology, 58(1), pp. 51-61.

Williams, C. and Leuwer, M. (2010) 'Neuromuscular blocking agents and skeletal muscle relaxants', Side Effects of Drugs Annual, pp. 273-280. doi: 10.1016/ s0378-6080(10)32012-5. 